\title{
Drugs potentially affecting the extent of airways reversibility on pulmonary function testing are frequently consumed despite guidelines
}

This article was published in the following Dove Press journal:

International Journal of COPD

8 August 2013

Number of times this article has been viewed

\author{
Terry E Jones' \\ AnneMarie Southcott ${ }^{2}$ \\ Sean Homan ${ }^{3}$ \\ 'Pharmacy Department, The Queen \\ Elizabeth Hospital, Woodville \\ South, SA, ${ }^{2}$ Respiratory and Sleep \\ Medicine, Western Health, Footscray, \\ VIC, ${ }^{3}$ Respiratory Unit, The Queen \\ Elizabeth Hospital, Woodville South, \\ SA, Australia
}

Background: The increase in forced expiratory volume in one second $\left(\mathrm{FEV}_{1}\right)$ effected by a bronchodilator is routinely assessed when patients undertake pulmonary function testing (PFT). Several drug classes can theoretically affect the magnitude of the increase in FEV . Withholding periods are advised for many but not all such drugs. Anecdotally, many subjects presenting for PFT are found to have taken drugs that might affect the test. We did an audit of patients presenting for PFT to assess the frequency with which $\mathrm{FEV}_{1}$ reversibility might be affected by drugs.

Methods: One hundred subjects presenting to the laboratory for PFT were questioned about recent drug consumption by an independent pharmacy intern. Reversibility of FEV ${ }_{1}$ was assumed to have been affected if drugs of interest were consumed within defined withholding periods or two half-lives for drugs without such data.

Results: Sixty-three subjects were prescribed drugs likely to affect FEV, reversibility. Thirtysix subjects consumed at least one such drug within the withholding period. Half (18) of these patients consumed $\beta$-blockers with or without $\beta$-agonists. Sixty-five subjects did not recall receiving any advice about withholding drugs prior to the test and only 10 recalled receiving advice from their clinician or pulmonary function technician.

Conclusion: Subjects presenting for PFT are infrequently advised to withhold drugs that may affect $\mathrm{FEV}_{1}$ reversibility, and consequently, often take such drugs close to the time of the test. Therefore, it is likely that the increase in $\mathrm{FEV}_{1}$ is frequently affected by interference from drugs and this might impact on diagnosis and/or treatment options.

Keywords: lung function tests, beta-adrenergic agonists, beta-adrenergic antagonists, withholding periods, bronchodilators

\section{Introduction}

Pulmonary function testing (PFT) usually includes an assessment of the forced expiratory volume in one second $\left(\mathrm{FEV}_{1}\right)$ before and after inhalation of a bronchodilator. The resulting increase in $\mathrm{FEV}_{1}\left(\Delta \mathrm{FEV}_{1}\right)$ is valuable in both the diagnosis and management of reversible airways disease. Authoritative guidelines on how PFTs should be conducted have been published by a combined task force of the American Thoracic Society and the European Respiratory Society. ${ }^{1}$ When the PFT is performed to demonstrate whether airflow reversibility is present, the guidelines recommend a baseline test be performed when the patient is "not taking any drugs prior to the test". This advice is presumably given to reduce the likelihood that any of the metrics will be affected by prior drug use. Drugs likely to affect the caliber of the airways include beta-adrenergic agonists ( $\beta$-agonists) and antagonists ( $\beta$-blockers) and other bronchodilators.
Correspondence: Terry E Jones Pharmacy Department, The Queen Elizabeth Hospital, 28 Woodville Rd Woodville South, SA 50I I, Australia Tel +61882226000 Fax+6I882226019 Email terry.jones@health.sa.gov.au 
The likelihood that any particular drug will affect any of the PFT metrics will depend on the number of molecules in the vicinity of the receptor at the time of the test, which is dependent upon the half-life of the drug. The guidelines recommend a four-hour withholding period for short-acting $\beta$-agonists (SABA) and ipratropium, and a 12-hour withholding period for long-acting $\beta$-agonists (LABA) and aminophylline/theophylline. There are no recommended withholding periods for the long-acting anticholinergic bronchodilator, tiotropium, ultralong-acting $\beta$-agonists (eg, indacaterol) or $\beta$-blockers.

Historically, it has been unlikely that patients taking $\beta$-blockers would have presented for PFT because these drugs were seen as relatively contraindicated in patients with airways disease. However, the magnitude of benefit afforded by $\beta$-blockers in heart failure and myocardial infarction is such that some advocate their use even when patients have reversible airways disease, although many advocate careful patient selection and/or PFT. ${ }^{2-9}$ While there are several studies on $\beta$-blocker use in patients with airways disease in the literature, they are typically limited by short duration of therapy, patient selection, or retrospective study design. A meta-analysis of 19 single-dose and 10 "continued treatment" (three days to four weeks) studies of cardioselective $\beta$-blocker use in patients with reactive airways disease concluded that these agents " ... should not be withheld in patients with reactive airways disease or COPD". ${ }^{3}$ The analysis revealed a decrease in $\mathrm{FEV}_{1}$ of $7.5 \%$ in the single-dose studies (baseline $\mathrm{FEV}_{1} 2.4 \mathrm{~L}$ ) and of only $0.4 \%$ in the "continued treatment studies" (baseline $\mathrm{FEV}_{1}$ $1.8 \mathrm{~L}$ ). However, there were many limitations in the studies analyzed (noted by the authors), including methodological concerns, too few participants, and only moderate disease severity. In addition, the longest period of treatment was four weeks, which is too short to reliably capture events that might trigger airways reactivity, including upper respiratory tract infections and seasonal allergies.

Anecdotal evidence suggests that patients were presenting for PFT soon after consuming drugs that might affect $\triangle \mathrm{FEV}_{1}$ and that, on occasion, a "negative" result (ie, one where the increase in $\mathrm{FEV}_{1}$ was minimal) was interpreted as being safe to prescribe $\beta$-blockers. Therefore, we undertook an audit of 100 consecutive patients to assess the frequency

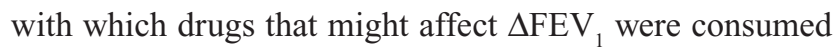
within a defined withholding period.

\section{Materials and methods}

Patients presenting to our hospital pulmonary function laboratory, which is accredited by the Thoracic Society of
Australia and New Zealand, were interviewed by a pharmacy intern either immediately prior to or after their planned PFT. Laboratory staff were only informed that a student counseling project was being conducted, so as to not affect usual practice of providing advice on withholding drugs of interest prior to PFT. Subjects were questioned about all drugs consumed (prescribed, over-the-counter, cigarettes, alternative drugs), when they were taken, what advice was provided about withholding drugs prior to the PFT, and by whom the advice was provided.

Our laboratory practice is to perform a baseline $\mathrm{FEV}_{1}$ and to repeat the test five minutes after inhaling four puffs of salbutamol $100 \mu \mathrm{g}$ via a large-volume $(750 \mathrm{~mL})$ spacer. We assumed that the increase in $\mathrm{FEV}_{1}$ would be affected by drugs if taken within the recommended withholding times (advised by the American Thoracic Society/European Respiratory Society guidelines). For tiotropium (no guidelines available), we adopted a 24-hour withholding period. For $\beta$-blockers, we adopted a withholding period equal to twice the reported half-life in normal subjects, ie, 12 hours for metoprolol and carvedilol, 20 hours for atenolol, and 24 hours for bisoprolol and sotalol.

\section{Results}

One hundred "consecutive" patients (ie, convenience sampling) were interviewed. Fifty-one subjects were referred from respirologists and 10 from cardiologists. Twenty-six subjects were inpatients at the time of their PFT. Sixty-three subjects were taking drugs likely to affect PFT. Thirteen subjects were current smokers, four of whom had smoked within the recommended withholding period (one hour) prior to PFT.

Thirty-six subjects had taken at least one drug likely to affect $\triangle \mathrm{FEV}_{1}$ within the withholding period (Table 1). Of these, 18 were taking $\beta$-blockers (Table 2 ) and of these 18 , six were also taking $\beta$-agonists (three combination inhaled corticosteroid/LABA, five SABA) and four were also prescribed anticholinergic bronchodilators. Because of the long half-life involved and the usual habit of taking drugs in the

Table I Demographics for 100 patients audited regarding drugs consumed prior to pulmonary function testing

\begin{tabular}{ll}
\hline Number taking drugs every day & 95 \\
Number of patients taking potentially interfering drugs & 63 \\
Number of PFTs potentially affected by I drug & 21 \\
Number of PFTs potentially affected by 2 drugs & 6 \\
Number of PFTs potentially affected by 3 drugs & 8 \\
Number of PFTs potentially affected by 4 drugs & I \\
\hline
\end{tabular}

Abbreviation: PFT, pulmonary function testing. 
Table 2 Drugs affecting pulmonary function testing

\begin{tabular}{llll}
\hline Drug class & $\begin{array}{l}\text { Number used } \\
\text { by patients }\end{array}$ & $\begin{array}{l}\text { Number of } \\
\text { tests affected }\end{array}$ & $\begin{array}{l}\text { Number } \\
\text { deliberately } \\
\text { withheld }\end{array}$ \\
\hline SABA & 47 (17 nebulizers) & 4 & 8 \\
LABA & 31 & 17 & 10 \\
Tiotropium & 18 & 11 & 5 \\
$\beta$-blockers & 18 & 17 & 1 \\
\hline
\end{tabular}

Notes: PFTs were considered affected if the drug was taken within the withholding period or $2 \times$ half-life value quoted in the product monograph. Drugs were considered deliberately withheld if advice was given to not take them prior to the test.

Abbreviations: PFT, pulmonary function testing; LABA, long-acting beta agonists; SABA, short-acting beta agonists.

morning, most subjects taking $\beta$-blockers consumed them within our defined withholding period (Table 2). Four of the 10 patients $(40 \%)$ referred by cardiologists and seven of the $51(13.7 \%)$ patients referred by respirologists were taking $\beta$-blockers.

Sixty-five subjects did not recall receiving any advice about withholding drugs prior to their PFT, 23 recalled seeing generic advice on the appointment card only, six recalled verbal advice being given by their doctor, and four recalled receiving verbal advice from PFT laboratory staff.

Of the 26 inpatients referred for PFT, five were prescribed nebulized salbutamol and three PFTs were considered to be affected. One of the others did not have the nebulizer within four hours of the PFT (ie, accidental withholding) and the remaining subject had the nebulizer withheld by the requestor of the test because of the PFT (ie, deliberate withholding).

\section{Discussion}

Almost two thirds of patients were prescribed at least one drug that might affect $\triangle \mathrm{FEV}_{1}$. Given the authoritative guidelines recommending withholding such drugs, we were surprised that almost $60 \%$ did not withhold them. Our accredited laboratory conducts more than 1000 PFTs annually and is typical of many public hospital PFT laboratories in Australia. Advice on withholding drugs was clearly suboptimal and warrants greater attention.

Of the 18 patients prescribed $\beta$-blockers, six were also prescribed bronchodilators (three LABA, five SABA, two tiotropium, and two ipratropium). Coprescription of $\beta$-blockers and $\beta$-agonists has been observed before, and while we did not investigate the reasons for the coprescription, this might be as a consequence of "compartmentalization" of respiratory and cardiac problems. ${ }^{5,8,10}$

Because we did not want to affect normal laboratory practice of providing advice on withholding drugs likely to affect $\Delta \mathrm{FEV}_{1}$, we were unable to repeat the PFT in the same laboratory on a proximate day when such drugs were withheld. Therefore we can only speculate about the effect on the magnitude of $\triangle \mathrm{FEV}_{1}$ caused by prior use of these drugs.

Superficially, it might be assumed that prior $\beta$-blocker consumption would lessen $\Delta \mathrm{FEV}_{1}$ (via competition with agonist salbutamol) while prior $\beta$-agonist consumption might enhance $\Delta \mathrm{FEV}_{1}$ (by increasing the number of agonist molecules). The potential effect is more complex and would depend on the numbers of agonist/antagonist molecules in the vicinity of the $\beta$-receptor, the numbers of $\beta$-receptors available, and the relative affinities of these molecules for the receptors. If salbutamol $400 \mu \mathrm{g}$ maximally dilated the bronchioles, then post-bronchodilator $\mathrm{FEV}_{1}$ could not be increased by prior $\beta$-agonist use, but baseline $\mathrm{FEV}_{1}$ would likely be elevated (and hence $\Delta \mathrm{FEV}_{1}$ would be reduced). However, if salbutamol $400 \mu \mathrm{g}$ was insufficient to dilate the bronchioles maximally, then prior $\beta$-agonist use might elevate both prebronchodilator and post-bronchodilator $\mathrm{FEV}_{1}$, and if the magnitude of the effect on both was similar, $\Delta \mathrm{FEV}_{1}$ would be unaffected.

The effect of prior use of $\beta$-blockers would also depend upon the numbers of agonist and antagonist molecules (and their respective affinities) in the vicinity of $\beta$-receptors. If there were few endogenous agonist molecules present, baseline $\mathrm{FEV}_{1}$ would likely not be affected by prior $\beta$-blocker use, and if salbutamol $400 \mu \mathrm{g}$ produced just maximal or submaximal bronchodilatation, then $\beta$-blockers would likely reduce post-bronchodilator $\mathrm{FEV}_{1}$. In this scenario, the $\Delta \mathrm{FEV}_{1}$ would be reduced. However, if there were endogenous $\beta$-agonist molecules present, baseline $\mathrm{FEV}_{1}$ would likely be reduced, and if the post-bronchodilator FEV, was similarly reduced, $\Delta \mathrm{FEV}_{1}$ might be unaffected. A final scenario would be if salbutamol $400 \mu \mathrm{g}$ greatly exceeded the dose required for maximal bronchodilatation, then prior $\beta$-blocker use may not reduce post-bronchodilator $\mathrm{FEV}_{1}$ and, unless baseline $\mathrm{FEV}_{1}$ was reduced, $\triangle \mathrm{FEV}_{1}$ would be unaffected. This can be explained diagrammatically via "dose-response" curves (Figures 1-3) where the "effective dose" (horizontal axis) represents the net effect. This net effect consists of the sum of both endogenous and exogenous $\beta$-agonist molecules minus exogenous $\beta$-blocker antagonist molecules.

Published data suggest that salbutamol $400 \mu \mathrm{g}$ is insufficient to produce maximal/supramaximal bronchodilatation and hence the scenarios in Figure 1B, Figure 2B, and Figure 3B are unlikely. In a study of 24 subjects with chronic obstructive pulmonary disease, the greatest relative increase in $\mathrm{FEV}_{1}$ was achieved by increasing the salbutamol dose from 
A

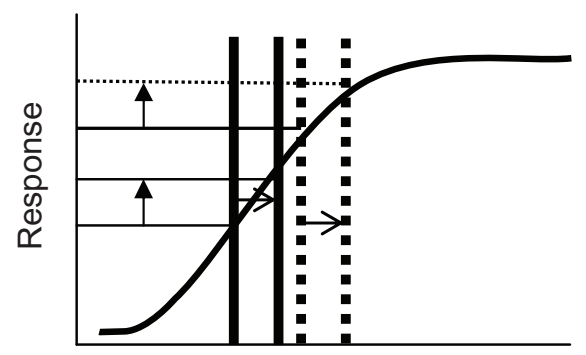

Effective dose
B

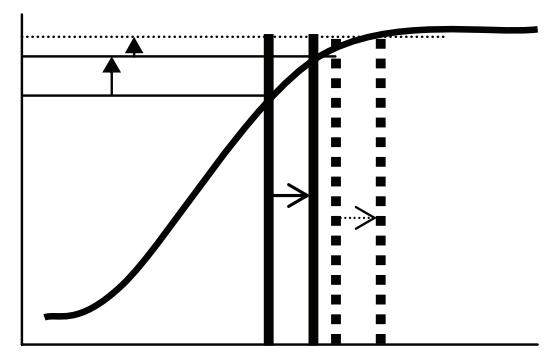

Effective dose

Figure I Effect of prior $\beta$-agonist use on magnitude of FEV , increase (vertical arrows) if salbutamol $400 \mu$ g produces less-than-maximal bronchodilatation (A) or maximal bronchodilatation (B). Solid lines represent the situation (pre and post salbutamol $400 \mu \mathrm{g}$ ) that would have occurred without prior use of $\beta$-agonist and dotted lines represent the situation (pre and post salbutamol $400 \mu \mathrm{g}$ ) that would have occurred in the presence of the $\beta$-agonist. (A) Prior use of $\beta$-agonist moves the "effective dose" to the right (more agonist molecules present) but the response (magnitude of increase in $\mathrm{FEV}_{1}$ ) is unaffected because the shift occurs on the linear portion of the curve. (B) Prior use of a $\beta$-agonist moves the "effective dose" to the right but the response (magnitude of increase in FEV) is greatly reduced because the shift occurs on the nonlinear portion of the curve.

Abbreviation: $\mathrm{FEV}_{1}$, forced expiratory volume in one second.

A

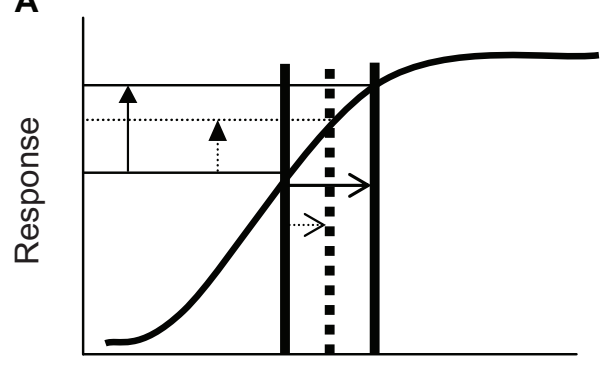

Effective dose
B

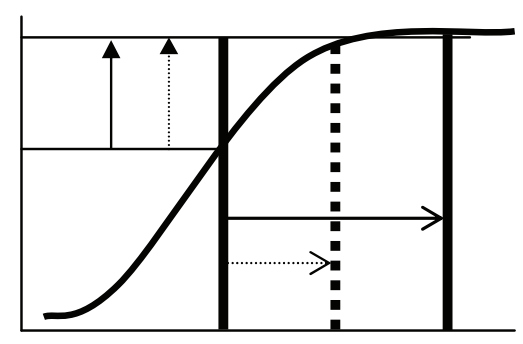

Effective dose

Figure 2 Effect of prior use of $\beta$-blocker on magnitude of FEV increase (vertical arrows) if salbutamol 400 $\mu$ g produces just-maximal bronchodilatation (A) or is more than sufficient to produce maximal bronchodilatation (B) If baseline FEV is unaffected by $\beta$-blocker. Solid lines represent the situation (pre and post salbutamol $400 \mu \mathrm{g}$ ) that would have occurred without prior use of $\beta$-blocker and the dotted line represents the situation (post salbutamol $400 \mu \mathrm{g}$ ) that would have occurred in the presence of $\beta$-blocker. (A) Baseline FEV , unaffected by a $\beta$-agonist (no endogenous agonist molecules present) but the response (magnitude of increase in FEV) is greatly reduced due to competition for $\beta$-receptors by agonist and antagonist molecules (an effect equivalent to reducing the "effective dose"). (B) Baseline FEV, unaffected by the $\beta$-agonist, and the response (magnitude of increase in $\mathrm{FEV}_{1}$ ) is unaffected because excess $\beta$-agonist molecules effectively compete for $\beta$-receptors and while the "effective dose" is reduced, the response remains maximal.

Abbreviation: $\mathrm{FEV}_{1}$, forced expiratory volume in one second.

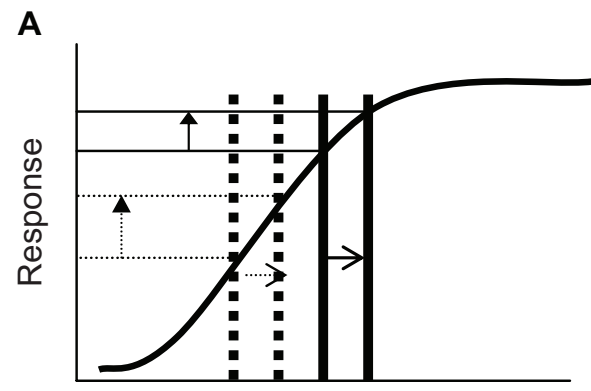

Effective dose
B

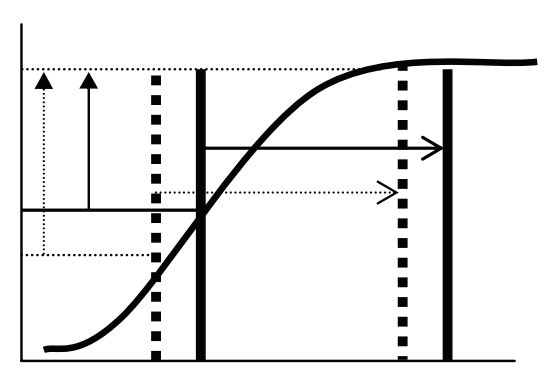

Effective dose

Figure 3 Effect of prior use of $\beta$-blockers on magnitude of $\mathrm{FEV}_{1}$ increase (vertical arrows) if salbutamol $400 \mu \mathrm{g}$ produces less than maximal bronchodilatation (A) or is more than

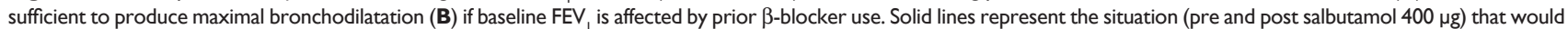
have occurred without prior use of $\beta$-blocker and dotted lines represent the situation (pre and post salbutamol $400 \mu \mathrm{g}$ ) that would have occurred in the presence of $\beta$-blocker. (A) Prior use of a $\beta$-agonist moves "effective dose" to the left (access to $\beta$-receptors by salbutamol is reduced) but the response (magnitude of increase in FEV ) is unaffected because the shift is on the linear part of the curve. (B) Prior use of a $\beta$-agonist moves the "effective dose" to the left (access to $\beta$-receptors by salbutamol is reduced) but the response (magnitude of increase in $\mathrm{FEV}_{1}$ ) is increased because the shift occurs on the nonlinear portion of the curve. Whether the response would be an increase, no change or a decrease in response would depend upon the relative effects of the $\beta$-agonist on baseline and post-bronchodilator FEV, and where these values sit on the dose-response curve. Abbreviation: $\mathrm{FEV}_{1}$, forced expiratory volume in one second. 
$20 \mu \mathrm{g}$ to $50 \mu \mathrm{g}$, but an increase in $\mathrm{FEV}_{1}$ was observed over the entire salbutamol range of $20-800 \mu \mathrm{g}$, with an additional $2.6 \%$ being attained by increasing the dose from $400 \mu \mathrm{g}$ to $800 \mu \mathrm{g} .{ }^{11}$ Another study that examined the dose-response effect on $\mathrm{FEV}_{1}$ in healthy subjects and mild/moderate asthmatics showed a continued increase in $\mathrm{FEV}_{1}$ over the range of $10-800 \mu \mathrm{g} .{ }^{12}$

The American Thoracic Society/European Respiratory Society guidelines advise that the post-bronchodilator FEV should be measured 10-15 minutes after the last of four puffs of salbutamol, but our laboratory uses an interval of only 5 minutes. ${ }^{1}$ This might lower the frequency with which airways reversibility is diagnosed by our laboratory. These guidelines also allow the test requestor to choose the bronchodilator (and dose). In our laboratory, it is rare for the test requestor to specify either the bronchodilator drug or dose, and none of the patients in this study had such a request.

Eleven of the 18 patients prescribed tiotropium took it within the withholding period. Whether prior use of this anticholinergic bronchodilator would affect $\triangle F E V_{1}$ would depend on the relative effect of tiotropium on both

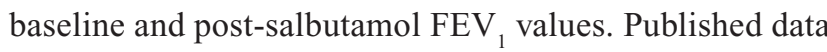
suggest anticholinergic agents provide bronchodilatation additional to salbutamol. In a study of 20 patients with chronic obstructive pulmonary disease, $5 \mathrm{mg}$ of nebulized salbutamol produced an increase in $\mathrm{FEV}_{1}$ similar to that of ipratropium $500 \mu \mathrm{g}$ and this effect was additive. ${ }^{13}$ In the recently published UPLIFT study, participants received ipratropium $80 \mu \mathrm{g}$ followed by salbutamol $400 \mu \mathrm{g}$, and post-bronchodilator $\mathrm{FEV}_{1}$ was determined 30 minutes later. ${ }^{14}$ Although the participants in UPLIFT were diagnosed with chronic obstructive pulmonary disease (on the basis of age, smoking history, and PFT results), 54\% experienced a $\Delta \mathrm{FEV}_{1}$ of $\geq 12 \%$ and $\geq 200 \mathrm{~mL}$, ie, consistent with an acute bronchodilator response. ${ }^{15}$ The additional bronchodilator effect can serve to blur the laboratory distinction between asthma and COPD. ${ }^{16}$

Some of the PFT requests in our study might have been ordered to assess whether additional benefit might be afforded by escalating therapy. In such cases, the test requestor might require the PFT to be performed without withholding $\beta$-agonists or other drugs and this would be factored into the interpretation of results. However, it is also likely that some PFTs were requested to assess patient suitability for $\beta$-blocker therapy (especially requests from cardiologists). Seventeen of the 18 subjects prescribed $\beta$-blockers in this study took them within the withholding period. If $\Delta \mathrm{FEV}_{1}$ was modest (as a result of $\beta$-blocker consumption, ie, the scenario in
Figure 2A), this might have been interpreted as being safe to prescribe $\beta$-blockers. However, in reality, these patients might be at risk of bronchoconstriction. A caveat should be emphasized on the PFT report when a "negative" result (ie, $\triangle \mathrm{FEV}_{1}$ fails to reach $12 \%$ and $200 \mathrm{~mL}$ ) is observed, and this might be as a consequence of prior drug consumption, that it does not exclude the possibility of reversible airways disease.

We chose a withholding period twice that of the published half-life for $\beta$-blockers, but this may be too conservative, especially for nonselective $\beta$-blockers and for those drugs for which the half-life might be prolonged. Longer half-lives are likely for sotalol, bisoprolol, and atenolol because they are eliminated mainly via the renal route and many patients will have impaired renal function, if only as a consequence of ageing. The very long half-life of ultra-LABAs (eg, indacaterol, half life $\geq 40$ hours) would require long periods of abstinence (more than three days) if an effect on $\triangle \mathrm{FEV}_{1}$ was to be minimized.

Because we did not want to affect normal laboratory practice, we were unable to repeat the PFT in the same laboratory on a proximate day when drugs likely to affect $\triangle F E V_{1}$ were withheld, so we can only speculate about the actual effect on increase in $\mathrm{FEV}_{1}$ caused by these drugs.

\section{Disclosure}

This work was presented in poster form at the Thoracic Society of Australia and New Zealand National Scientific Conference, Brisbane, Australia, March 30-April 2, 2010. Otherwise, the authors report no conflicts of interest in this work.

\section{References}

1. Miller M, Hankinson J, Brusasco V, et al. Standardisation of spirometry. Eur Resp J. 2005;26:319-338.

2. Everly M, Heaton PC, Cluxton RJ. $\beta$-blocker underuse in secondary prevention of myocardial infarction. Ann Pharmacother. 2004;38: 286-293.

3. Salpeter SR, Ormiston TM, Salpeter EE. Cardioselective $\beta$-blockers in patients with reactive airway disease: a meta-analysis. Ann Intern Med. 2002; 137:715-725.

4. Gottlieb SS, McCarter RJ, Vogel RA. Effect of beta-blockade on mortality among high-risk and low-risk patients after myocardial infarction. N Engl J Med. 1998;339:489-497.

5. Chen J, Radford MJ, Wang Y, Marciniak TA, Krumholz HM. Effectiveness of beta-blocker therapy after acute myocardial infarction in elderly patients with chronic obstructive pulmonary disease or asthma. JAMA. 2001;37:1950-1956.

6. Egred M, Shaw S, Mohammed B, Waitt P, Rodrigues E. Under-use of beta-blockers in patients with ischaemic heart disease and concomitant chronic obstructive pulmonary disease. QJM. 2005;98:493-497.

7. Olenchock BA, Fonarow GG, Pan W, et al. Current use of beta blockers in patients with reactive airways disease who are hospitalised with acute coronary syndromes. Am J Cardiol. 2009;103:295-300. 
8. Short PM, Lipworth SIW, Elder DHJ, Schembri S, Lipworth BJ. Effect of $\beta$ blockers in treatment of chronic obstructive disease: a retrospective cohort study. BMJ. 2001:342.

9. Rutten FH, Zuithoff NPA, Hak E, et al. $\beta$-blockers may reduce mortality and risk of exacerbations in patients with chronic obstructive pulmonary disease. Arch Intern Med. 2010;170:880-887.

10. Ling Y, Saleem W, Shee CD. Concomitant use of $\beta$-blockers and 32-agonists. Eur Respir J. 2008;4:905-906.

11. Borrill ZL, Houghton CM, Woodcock AA, Vestbo J, Singh D. Measuring bronchodilation in COPD clinical trials. Br J Clin Pharmacol. 2004;59:379-384.

12. Houghton CM, Woodcock AA, Singh D. A comparison of lung function methods for assessing dose-response effects of salbutamol. Br J Clin Pharmacol. 2004;58:134-141.
13. Hadcroft J, Calverley PMA. Alternative methods for assessing bronchodilator reversibility in chronic obstructive disease. Thorax. 2001;56: 713-720.

14. Tashkin DP, Celli B, Senn S, et al. A 4-yr trial of tiotropium in chronic obstructive pulmonary disease. $N$ Engl J Med. 2008;359: 1543-1554.

15. Tashkin DP, Celli B, Decramer M, et al. Bronchodilator responsiveness in patients with COPD. Eur Respir J. 2008;31:742-750.

16. Soriano JB, Mannino DM. Reversing concepts on COPD irreversibility. Eur J Resp J. 2008;31:695-696.

\section{Publish your work in this journal}

The International Journal of COPD is an international, peer-reviewed journal of therapeutics and pharmacology focusing on concise rapid reporting of clinical studies and reviews in COPD. Special focus is given to the pathophysiological processes underlying the disease, intervention programs, patient focused education, and self management protocols.

\section{Dovepress}

This journal is indexed on PubMed Central, MedLine and CAS. The manuscript management system is completely online and includes a very quick and fair peer-review system, which is all easy to use. Visit http://www.dovepress.com/testimonials.php to read real quotes from published authors.

Submit your manuscript here: http://www.dovepress.com/international-journal-of-copd-journal 